\title{
Page Kidney: A Rare Cause of Resistant Hypertension Early After Renal Transplantation
}

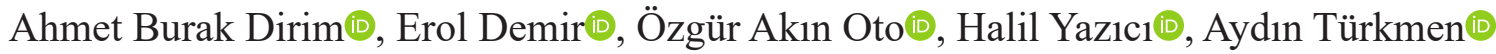

Division of Nephrology, Department of Internal Medicine, İstanbul School of Medicine, İstanbul University, İstanbul, Turkey

\begin{abstract}
A 21-year-old man underwent pre-emptive kidney transplantation from a living-related donor due to end-stage kidney disease with unknown etiology. Serum creatinine level decreased from $6.5 \mathrm{mg} / \mathrm{dL}$ to $1.6 \mathrm{mg} / \mathrm{dL}$ on the first day of transplantation. Postoperative Doppler ultrasonography was within normal limits. The following day, blood pressure increased up to 200/120 mmHg despite triple anti-hypertensive treatment. In addition, hemoglobin levels decreased from $9.4 \mathrm{~g} / \mathrm{dL}$ to $7.9 \mathrm{~g} /$ $\mathrm{dL}$. Therefore, the patient was evaluated for anemia and resistant hypertension.
\end{abstract}

Post-transplant anemia is an overlooked diagnosis. Nevertheless, it has been reported with a prevalence of up to $90 \%$ in the early stages of kidney transplantation. The pathogenesis of post-transplant anemia is multifactorial. It includes allograft dysfunction, iron deficiency, surgical blood loss, drugs, inflammation, erythropoietin deficiency, and hemolysis. ${ }^{1,2}$ Likewise, postoperative hypertension is not rare in renal transplant recipients. It occurs due to allograft dysfunction, hypervolemia, postoperative pain, drug toxicity, or renal artery stenosis. ${ }^{3}$

Anti-thymocyte globulin and mycophenolic acid treatments were thought of as contributors to anemia in this case. Tacrolimus levels were within normal limits. No signs of hypervolemia or hemolysis were present. Pain management was adequate. Doppler ultrasonography showed no evidence of renal artery stenosis or hemorrhage

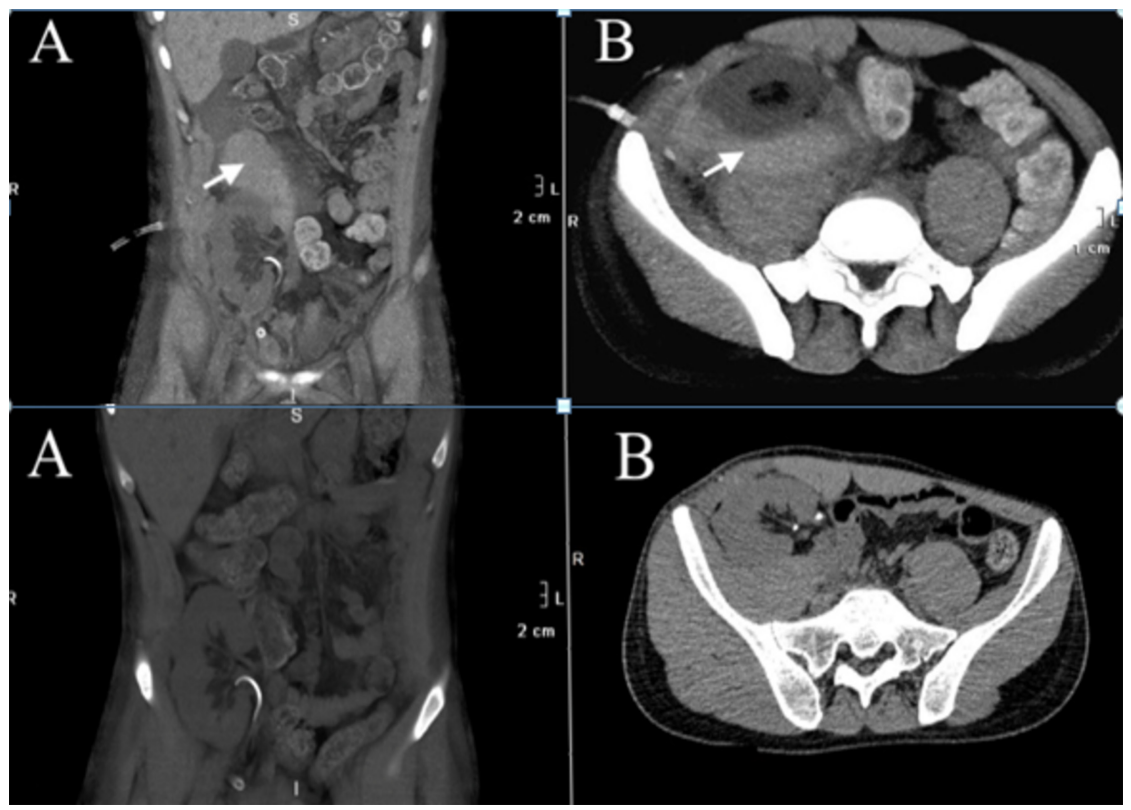

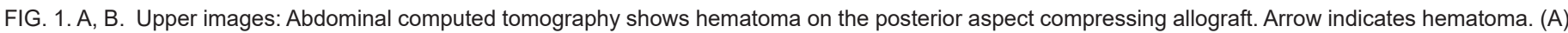
Coronal plane, (B) Axial plane. Lower images: Abdominal computed tomography after surgical hematoma removal. (A) Coronal plane, (B) Axial plane.

Corresponding author: Ahmet Burak Dirim, Division of Nephrology, Department of Internal Medicine, İstanbul School of Medicine, İstanbul University, İstanbul, Turkey e-mail: ahmetburakdirim@gmail.com

Received: July 10, 2021 Accepted: August 19, $2021 \cdot$ DOI: 10.5152/balkanmedj.2021.21059

Available at www.balkanmedicaljournal.org

ORCID iDs of the authors: A.B.D. 0000-0003-2262-8627; E.D. 0000-0003-0128-5645; O.A.O. 0000-0003-0928-8103; H.Y. 0000-0003-2526-3483; A.T. 0000-0003-3664-8469.

Cite this article as:

Dirim A, Demir E, Oto ÖA, Yazıcı H, Türkmen A. Page kidney: A rare cause of resistant hypertension early after renal transplantation. Balkan Med J. 2021;38(5):316-317.

Copyright@Author(s) - Available online at http://balkanmedicaljournal.org/ 
on postoperative day 1; nonetheless, computed tomography was performed to rule out hemorrhagic complications. It revealed a $6 \times 10 \times 15 \mathrm{~cm}$-sized hematoma on the posterior aspect of the allograft (Figure 1, upper images). Hence, Page kidney diagnosis was made.

Page kidney is a rare cause of hypertension in both native kidneys and allografts. Secondary hyperaldosteronism related to external compression drives the pathogenesis of this phenomenon. It can occur due to hematoma, urinoma, or lymphocele after trauma, biopsy, and surgical complications. ${ }^{4}$ It is usually related to subcapsular hematoma. However, a perirenal hematoma that compresses the kidney can also cause Page kidney, similar to the present case. ${ }^{5}$ After surgical hematoma evacuation, hemodynamic stabilization was restored rapidly (Figure 1, lower images)

Although postoperative hemorrhagic complications usually cause hypotension, Page kidney must be borne in mind as an exception.

Patient Consent for Publication: Written informed consent was obtained from the patient.
Author Contributions: Concept - A.B.D., E.D.; Supervision - A.T., H.Y.; Data Collection and/or Processing - E.D., Ö.A.O.; Literature Review - A.B.D., E.D.; Writing - A.B.D.

Acknowledgments: We would like to thank Dr. Berkay Dertsiz for English language editing.

Conflict of Interest: The authors has no conflict of interest to declare.

\section{REFERENCES}

1. Jones H, Talwar M, Nogueira JM, et al. Anemia after kidney transplantation; its prevalence, risk factors, and independent association with graft and patient survival: a time-varying analysis. Transplantation. 2012;93(9):923-928. [CrossRef]

2. Winkelmayer WC, Chandraker A. Post-transplantation anemia: management and rationale. Clin J Am Soc Nephrol. 2008;3(2)(suppl 2):S49-S55. [CrossRef]

3. Thomas B, Taber DJ, Srinivas TR. Hypertension after kidney transplantation: a pathophysiologic approach. Curr Hypertens Rep. 2013;15(5):458-469. [CrossRef]

4. Efe O, McGrath MM, Hu FY, et al. Urinoma From surgical cyst rupture and page kidney phenomenon in a kidney transplant recipient. Kidney Med. 2021 February 11;3(2):307-308. [CrossRef]

5. Boggi U, Berchiolli R, Ferrari M, et al. Renal hypertension due to giant perirenal haematoma: permanent resolution by percutaneous ultrasound-guided drainage. Scand J Urol Nephrol. 1998;32(1):64-66. [CrossRef] 